\title{
Ectopic pregnancy: a comprehensive analysis of risk factors and management
}

\author{
Dinesh Pal Yadav*, Indra Bhati, Balgopal Singh Bhati
}

Department of Obstetrics and Gynaecology, Umaid Hospital, Dr. S.N. Medical College, Jodhpur, Rajasthan, India

Received: 15 June 2016

Accepted: 02 July 2016

\section{*Correspondence:}

Dr. Dinesh Pal Yadav,

E-mail: dineshpalyadav2@gmail.com

Copyright: (c) the author(s), publisher and licensee Medip Academy. This is an open-access article distributed under the terms of the Creative Commons Attribution Non-Commercial License, which permits unrestricted non-commercial use, distribution, and reproduction in any medium, provided the original work is properly cited.

\begin{abstract}
Background: Ectopic pregnancy is the most life threatening emergency in pregnancy leading to maternal death. Ectopic pregnancy jeopardizes the wish of attainment of motherhood also. Increase in incidence of pelvic inflammatory disease (PID), previous history of $\mathrm{D}$ and $\mathrm{C}$ and abortion, previous abdominal surgeries and use of assisted reproductive techniques are the various risk factors for ectopic pregnancy. The objective of this study was to assess the demographic profile, risk factors, clinical presentation and surgical management of ectopic pregnancy at a tertiary care centre.

Methods: A prospective, longitudinal and observational study was conducted in the department of obstetrics and gynaecology, Umaid Hospital, Dr. SN Medical College, Jodhpur during a period of one year from October 2014 to September 2015. 80 cases of ectopic pregnancy admitted in the hospital were analyzed in terms of demographic profile, risk factors, clinical presentation, management, morbidity, mortality. Finally all collected material and data were analyzed statistically to draw various informative conclusions.

Results: Most common age and parity affected by ectopic pregnancy were 21-30 years (63.75\%) and para 1-3 $(72.50 \%)$ respectively. No age and parity were immune to ectopic pregnancy. More than one clinical feature was present in most of the patients. Most common site of ectopic pregnancy was ampullary region (51.25\%) of the tube. Salpingectomy was the most common surgical procedure performed $(75 \%)$. Few patients had more than one complication. 29 cases had no complication. No maternal mortality occurred during this period. Around 50\% women received blood transfusion.

Conclusions: Ectopic pregnancy is a life-threatening condition occurring in women all over the world. As the incidence of ectopic pregnancy increases, ways and means have to be found to reduce the associated morbidity and mortality and to preserve future fertility.
\end{abstract}

Keywords: Ectopic pregnancy, Pelvic inflammatory disease, Salpingectomy

\section{INTRODUCTION}

Attainment of motherhood is the most cherished desire of every female. An ectopic pregnancy jeopardizes this wish and may permanently impair her reproductive capacity. Pregnancy is a perfection of marital bliss but no perfection is so absolute that impurity does not pollute so is the ectopic pregnancy. For a young maid whose womb is desirous of an offspring, advanced extra-uterine pregnancy is but an illaned opportunity which kills life or else its quality. Ectopic pregnancy is the most common life threatening emergency in early pregnancy. It is still a major health problem among the women of child-bearing age in our country and continues to be an important cause of morbidity and mortality in women. ${ }^{1}$ The rate of ectopic pregnancy is 11 per 1000 pregnancies, with a maternal mortality of 0.2 per 1000 estimated ectopic pregnancies. ${ }^{2}$ The marked increase was attributed to a number of 
factors including an increase in incidence of pelvic inflammatory disease (PID), smoking in women of reproductive age, use of assisted reproductive techniques and general awareness of the condition facilitated by development of early pregnancy assessment units (EPAUs). Improvement in non-invasive diagnostic methods, such as sensitive pregnancy tests in urine and serum and high-resolution trans-vaginal sonography, has enabled early diagnosis of ectopic pregnancy. ${ }^{3-5}$ As a consequence, the clinical presentation of ectopic pregnancy has changed from a life-threatening disease, necessitating emergency surgery, to a benign condition in frequently asymptomatic women for whom nonsurgical treatment options are available. ${ }^{3-5}$ As ectopic pregnancy has variable presentations from asymptomatic to life threatening condition, the aim of this study was to determine the clinical profile of patients presenting with ectopic pregnancy and to determine the risk factors, so as to make recommendations on interventions to reduce the incidence of this life-threatening condition.

\section{METHODS}

The present prospective, longitudinal and observational study was conducted in the department of obstetrics and gynaecology, Umaid hospital, Dr. SN Medical College, Jodhpur during a period of one year from October 2014 to September 2015. 80 cases of ectopic pregnancy admitted in the hospital were analyzed in terms of demographic profile, risk factors, clinical presentation, management, morbidity, mortality and associated risk factors. Finally all collected material and data were analyzed to draw various informative conclusions.

\section{RESULTS}

The most common age group and parity affected were 21-30 years $(63.75 \%)$ and para $1-3(72.50 \%)$ but none of the age and parity was immune to ectopic pregnancy. $80.00 \%$ women were Hindu and $57.50 \%$ women belong to rural dwelling (Table 1).

Table 1: Demographic picture of patients.

\begin{tabular}{|llllll|}
\hline AGE (years) & $<20$ & $20-25$ & $26-30$ & $31-35$ & $>35$ \\
\hline Parity & $9(11.25 \%)$ & $29(36.25 \%)$ & $22(27.50 \%)$ & $14(17.5 \%)$ & $6(7.50 \%)$ \\
\hline & 0 & $1-3$ & $4-7$ & 77 & \\
\hline Religion & $12(15 \%)$ & $58(72.50 \%)$ & $10(12.50 \%)$ & $0(0.0 \%)$ & \\
\hline & Hindu & Muslim & Others & & \\
\hline Residence & $64(80 \%)$ & $14(17.50 \%)$ & $2(2.50 \%)$ & & \\
\hline & Rural & Urban & & & \\
\hline
\end{tabular}

Table 2: Distribution of cases according to clinical presentation.

\begin{tabular}{|lll|}
\hline Symptoms & No. of cases & Percentage \\
\hline Amenorrhea & 57 & 71.25 \\
\hline Pain abdomen & 69 & 86.25 \\
\hline Bleeding per vaginum & 46 & 57.50 \\
\hline Fainting & 18 & 22.50 \\
\hline Shoulder pain & 5 & 6.25 \\
\hline Bladder symptoms & 3 & 3.75 \\
\hline Fever & 6 & 7.50 \\
\hline Vomiting & 10 & 12.50 \\
\hline Passing of fleshy cast & 3 & 3.75 \\
\hline
\end{tabular}

More than one clinical feature was present in most of the patients. Amenorrhea (71.25\%) and pain abdomen $(86.25 \%)$ were the common presenting symptoms while tenderness in fornices $(60 \%)$, tender cervical movement $(52.50 \%)$ and Fullness in fornices $(51.25 \%)$ were the common signs. $13.75 \%$ women presented in shock. $67.50 \%$ patients presented with ruptured ectopic pregnancy (Table 2 and Table 3 ).
Table 3: Distribution of cases according to clinical signs in ectopic pregnancy.

\begin{tabular}{|lll|}
\hline Clinical sign & No. of cases & Percentage \\
\hline Shock & 11 & 13.75 \\
\hline Abdominal distension & 17 & 21.25 \\
\hline Abdominal tenderness & 30 & 37.50 \\
\hline Abdominal mass & 3 & 3.75 \\
\hline $\begin{array}{l}\text { Cervical movement } \\
\text { tenderness }\end{array}$ & 42 & 52.50 \\
\hline Fullness in fornices & 41 & 51.25 \\
\hline Tenderness in fornix & 48 & 60.00 \\
\hline Adnexal mass & 14 & 17.50 \\
\hline
\end{tabular}

The most common risk factor found was PID. It was present in $20(25.00 \%)$ cases of ectopic pregnancy. History of $\mathrm{D}$ and $\mathrm{C}$ and previous abdominal surgery were other common risk factor. Four cases had a previous ectopic pregnancy. In $18(22.50 \%)$ patients no risk factor was present. Relative risk after previous one ectopic pregnancy was $5.00 \%$ (Table 4 ).

The most common site of ectopic pregnancy was tubal $(93.75 \%)$ of which ampullary region of the tube was most 
commonly affected. Rudimentary horn pregnancy was seen in 2 cases. Two cases of ovarian pregnancy and one case of secondary abdominal pregnancy was seen (Table $5)$.

Table 4: Distribution of cases according to predisposing risk factors.

\begin{tabular}{|lll|}
\hline Predisposing risk factor & No. of cases & Percentage \\
\hline PID & 20 & 25.00 \\
\hline TB & 2 & 2.50 \\
\hline MTP & 9 & 11.25 \\
\hline Abortion & 17 & 21.25 \\
\hline Puerperal sepsis & 10 & 12.50 \\
\hline Infertility & 6 & 7.50 \\
\hline IUCD & 8 & 10.00 \\
\hline OCP & 7 & 8.75 \\
\hline Sterilization operation & 9 & 11.25 \\
\hline D and C & 18 & 22.50 \\
\hline $\begin{array}{l}\text { Previous abdominal } \\
\text { surgery LSCS }\end{array}$ & 15 & 18.75 \\
\hline $\begin{array}{l}\text { Previous ectopic } \\
\text { pregnancy }\end{array}$ & 4 & 5.00 \\
\hline
\end{tabular}

Table 5: Distribution of cases according to site of ectopic pregnancy.

\begin{tabular}{|lll|}
\hline Site & No. of cases & Percentage \\
\hline Tubal ampullary & 41 & 51.25 \\
\hline Tubal isthmic & 20 & 25.00 \\
\hline Tubal infundibulum & 13 & 16.25 \\
\hline Tubal interstitial & 1 & 1.25 \\
\hline Ovarian & 2 & 2.50 \\
\hline Rudimentary horn & 2 & 2.50 \\
\hline Abdominal & 1 & 1.25 \\
\hline
\end{tabular}

Conservative surgery in form of partial salpingectomy and milking of the tube was done in $10(12.50 \%)$ cases. Radical surgery was done in $70(87.50 \%)$ cases. The most commonly performed operation was unilateral salpingectomy. It was done in $60(75.00 \%)$ patients (Table 6).
Table 6: Distribution of cases according to management.

\begin{tabular}{|ll|l|}
\hline Site & $\begin{array}{l}\text { No. of } \\
\text { cases }\end{array}$ & Percentage \\
\hline Partial Salpingectomy & 8 & 10.00 \\
\hline Unilateral salpingectomy & 60 & 75.00 \\
\hline Unilateral salpingoophorectomy & 4 & 5.00 \\
\hline Unilateral oophrectomy & 2 & 2.50 \\
\hline $\begin{array}{l}\text { Extraction of IUD baby with } \\
\text { excision of rudimentary horn }\end{array}$ & 2 & 2.50 \\
\hline Milking of tube & 2 & 2.50 \\
\hline $\begin{array}{l}\text { Total abdominal hysterectomy } \\
\text { with bilateral salpingo- } \\
\text { oophrectomy }\end{array}$ & 1 & 1.25 \\
\hline $\begin{array}{l}\text { Laparotomy followed by } \\
\text { extraction of live child }\end{array}$ & 1 & 1.25 \\
\hline
\end{tabular}

Table 7: Distribution of cases according to maternal morbidity

\begin{tabular}{|ll|l|}
\hline & No. of cases & Percentage \\
\hline Anaemia & 40 & 50.00 \\
\hline Shock & 11 & 13.75 \\
\hline Fever & 6 & 7.50 \\
\hline Paralytic ilieus & 1 & 1.25 \\
\hline UTI & 3 & 3.75 \\
\hline Wound infection & 1 & 1.25 \\
\hline ARDS & 1 & 1.25 \\
\hline
\end{tabular}

Pallor was seen in $50.00 \%$ cases. 29 cases had no complication. Few patients had more than one complication. No maternal mortality occurred during this period (Table 7).

Blood transfusion was required in $40(50.00 \%)$ cases. 33 $(34.37 \%)$ patients received 1-2 units of blood. Only 1 patient needed 6 units blood. Haemoperitoneum was present in $74(92.50 \%)$ cases. Maximum patients 46 $(57.5 \%)$ had a haemoperitoneum less than $500 \mathrm{ml}$. In 6 $(7.50 \%)$ cases about 1500 or more blood was found in the peritoneal cavity (Table 8).

Table 8: Distribution of cases according to haemoperitoneum and blood transfusion

\begin{tabular}{|lllllll|}
\hline $\begin{array}{l}\text { A mount of } \\
\text { haemoperitoneum }\end{array}$ & Absent & $<500 \mathrm{ml}$ & $\mathbf{5 0 0 - 1 0 0 0 ~} \mathrm{ml}$ & $\begin{array}{l}\mathbf{1 0 0 0 - 1 5 0 0} \\
\mathrm{ml}\end{array}$ & $>1500 \mathrm{ml}$ \\
\hline & $6(7.50 \%)$ & $46(57.50 \%)$ & $18(22.50 \%)$ & $4(5.00 \%)$ & $6(7.50 \%)$ & \\
\hline Blood transfusion & Not received & $\mathbf{1}$ unit & $\mathbf{2}$ unit & $\mathbf{3}$ unit & $\mathbf{4}$ unit & $\mathbf{6}$ unit \\
\hline & $40(50.00 \%)$ & $14(17.50 \%)$ & $18(22.50 \%)$ & $5(6.25 \%)$ & $2(2.50 \%)$ & $1(1.25 \%)$ \\
\hline
\end{tabular}

\section{DISCUSSION}

Ectopic pregnancy is a common obstetrical disorder in early pregnancy all over the world that remains an important cause of maternal morbidity and mortality. 80 cases of ectopic pregnancy, those were surgically managed, were analyzed over one year of period. In our study ectopic pregnancies were encountered in women 
between ages 18 to 40 years. Highest incidence of ectopic pregnancy was found in the age group of 21-30 years $(63.75 \%)$ and minimum incidence was found in age group $>35$ years $(7.50 \%)$. It shows that reproductive age group is more prone to ectopic pregnancy. It is because increase incidence of sexually transmitted diseases and pelvic inflammatory diseases in this age group as well as efficacy of antibiotic treatment for PID. Most common age group involved was 21-30 years for ectopic pregnancy as reported by Mandelkar et al, Vyas and Vaidya et al, A Panti et al, Premlata M et al. ${ }^{6-9}$

Highest incidence of ectopic pregnancy was in para 1-3 (72.50\%) and lowest incidence in para 4-7 (12.50\%). Twelwe patients were nulliparous. It was found more in Para 1-3 because of increased use of intra uterine contraceptive devices for births spacing and increased tubal ligation in these patients as this is the time for small family norm, early marriage, and early completion of family and use of family planning methods. These findings correlate with the observations of Pendse et al, Jophy R et al, Premlata $M$ et al where average parity was found to be $2-3{ }^{9-11}$ Whereas Majhi AK et al, Panti A et al found maximum incidence in nuliparous. ${ }^{8,12}$

Pain abdomen was the most common complaint in $86.25 \%$ cases. Its severity ranged from mild ache to cramp to a sudden, sharp pain which was generally localized to lower abdomen. This observation is compatible with observation of most of the author's like Gupta et al, Vyas and Vaidhya, Majhi AK et al, AO Lgwegbe et al and Premlata $\mathrm{M}$ et al. ${ }^{7,9,12-14}$ However lower figures were reported by Choudhary $\mathrm{R}$ and Pendse. ${ }^{10,15}$

Amenorrhea was present in $57(71.25 \%)$ of cases, the duration varying from 5 weeks to 9 months. These observation are in accordance with those of Pendse, Gupta et al, Vyas and Vaidya, Jophy et al and Majhi AK et al. ${ }^{7,11-13}$ Higher figures were given by Premlata $\mathrm{M}$ et al. ${ }^{9}$

On bimanual per vaginal examination painful cervical movement was found in $52.50 \%$ cases. It was because of recently effused blood in the pouch of douglas. These findings were compatible with finding of Jophy et al, Gupta et al. ${ }^{11,13}$ Higher figures were given by Vyas and Vaidya, Pendse, Majhi AK et al and Premlata $M$ et al. $7,9,10,12$

Fullness in fornices was found in 41 (51.25\%) cases. It was because of gradual disintegration of tubal wall followed by slow leakage of blood into the tubal lumen and peritoneal cavity. This gradually trickling blood collects in the pelvis, more or less walled off by adhesions resulting in pelvic hematocoele. Similar observations were reported by Pendse and Vyas and Vaidya. ${ }^{7,10}$
Forniceal tenderness was found in $48(60.00 \%)$ cases in present series. Slight higher incidence were observed by Vyas and Vaidya and A Panti et al. ${ }^{7,8}$

The most common etiological factor was pelvic inflammatory disease. It was found to be present in 20 $(25.00 \%)$ cases this observation is in consonance with findings of Vyas and Vaidya and Jophy R et al, Abubakar A Panti et al, Premlata $M$ et al. ${ }^{7,9,8,11}$ Pelvic inflammatory diseases are responsible for causing peritubal adhesions, partial closure of lumen, intra-tubal adhesions, diverticuli and cysts. In the diverticuli the myoelectrical activity is diminished and limited to that segment of the tube only and therefore the fertilized ovum gets trapped in it.Lower incidence was reported by Pendse and Gupta et al. ${ }^{10,13}$

History of D and C was present in 18 (22.50\%) cases. The indication was incomplete abortions, DUB etc. These observations are compatible with findings of Gupta et al,Vyas and Vaidya and Premlata $\mathrm{M}$ et al. ${ }^{7,9,13}$ Improper hygiene and sepsis while performing $\mathrm{D}$ and $\mathrm{C}$ can lead to PID, increasing the risk of ectopic pregnancy. History of previous abdominal surgery was present in 15 (18.75\%) patients. Similar finding have been reported by Majhi AK et al. ${ }^{12}$ Lower incidence were reported by Gupta et al, Pendse, Vyas and Vaidya respectively. ${ }^{7,10,13}$ The cause of ectopic pregnancy following abdominal surgery was observed by other authors to be peritubal adhesions and scarring which were found to be responsible for the occurrence of ectopic pregnancy.

Currently ultrasound and serum biomarkers are used by clinicians for early diagnosis. To conclude patients having clinical features of ectopic pregnancy on ultrasound scan as positive adnexal mass with or without gestational sac, with or without fetal heart, or presence of adnexal mass along with haemoperitoneum along with positive pregnancy test assures diagnosis of ectopic pregnancy. In our study $82.50 \%$ patients present with rupture ectopic pregnancy so early diagnosis and management is very important for decreasing the mortality and morbidity related with ectopic pregnancy.

Ectopic pregnancy was identified in the fallopian tube in $75(93.75 \%)$ of cases. In 2 cases pregnancy was found in rudimentary horn. Similar findings were reported by Vyas and Vaidhya, Majhi AK et al and Premlata $M$ et al. $^{7,9,12}$ Tubal ectopic pregnancies were ampullary in $51.25 \%$, isthmic in $25.00 \%$, fimbrial in $16.25 \%$ and interstitial in $1.25 \%$ cases. Similar findings are reported Vyas and Vaidya and A Panti et al. ${ }^{7,8}$

In our study $82.50 \%$ patients present with rupture ectopic pregnancy. Haemoperitoneum was absent in $6(7.50 \%)$ cases of the present series. About $57.50 \%$ patients had $<500 \mathrm{ml}$ blood, $22.50 \%$ cases had $500-1000 \mathrm{ml}, 5 \%$ patients had $1000-1500 \mathrm{ml} .7 .50 \%$ cases had $>1500 \mathrm{ml}$ blood in their peritoneal cavity. These finding are similar of those of Jophy et al and Vyas and Vaidya. ${ }^{711}$ In our study $40(50 \%)$ patients required blood transfusion. Most 
(40\%) required only one and two unit blood but $8(10 \%)$ patients who had massive haemoperitoneum required $\geq 3$ units of blood. Gupta et al reported similar findings. ${ }^{13}$

Majority of cases were of ruptured ectopic pregnancies with massive haemoperitoneum, where repair of tube was not possible, hence salpingectomy $(75.00 \%)$ was the commonest life-saving surgical procedures performed. Similarly various studies also reported that salpingectomy was the commonest operative procedure performed. Similar finding were given by Mandelekar, Vyas and Vaidya and Jophy et al. ${ }^{6,7,11}$

Salpinghoopherectomy was performed in $5.00 \%$ cases. We should conserve ovary as far as possible because of the assisted reproductive technologies which can be advised to woman in future. The only indication for the removal of ipsilateral ovary along with the tube is when it is diseased or involved in 'ectopic complex', in which hemostasis is best achieved by excising it. ${ }^{8}$

There was a significant degree of morbidity associated with ectopic pregnancy in this study, as shown by the results. This may be attributed to the delay in diagnosis and seeking treatment, and may have contributed to the slightly longer duration of hospitalization recorded. Anemia, which was the commonest complication in this study, was due to excessive blood loss from the rupture site, necessitating blood transfusion. Over the years, however, the therapy for ectopic gestation has evolved from a radical procedure to conservative treatment aimed at the preservation of fertility.

\section{CONCLUSION}

Ectopic pregnancy is a life-threatening condition occurring in women all over the world. As the incidence of ectopic pregnancy increases, ways and means have to be found to reduce the associated morbidity and mortality and to preserve future fertility. With emphasis shifting from radical to conservative therapy; prevention of risk factors and early diagnosis become very important.

Funding: No funding sources

Conflict of interest: None declared

Ethical approval: The study was approved by the Institutional Ethics Committee

\section{REFERENCES}

1. Vichnin, Michelle. Ectopic pregnancy in adolescents. Current Opinion in Obstetrics and Gynecology. 2008;20(5):475-8.
2. National Institute for Health and Clinical Excellence. Ectopic pregnancy and miscarriage: diagnosis and initial management in early pregnancy of ectopic pregnancy and miscarriage. December 2012. Available at http://guidance.nice.org.uk/.

3. Ankum WM, Mol BW, Van der Veen F, Bossuyt PM. Risk factors for ectopic pregnancy: a metaanalysis. Fertil Steril. 1996;65(6):1093-9.

4. Mol BW, Lijmer JG, Ankum WM, van der Veen F, Bossuyt PM. The accuracy of single serum progesterone measurement in the diagnosis of ectopic pregnancy: a meta-analysis. Hum Reprod. 1998;13(11):3220-7.

5. Farquhar CM. Ectopic pregnancy. Lancet. 2005;366(9485):583-91.

6. Mandelkara, Krishna UR, Varkey A. Ectopic pregnancy and fertility control. J Obstet Gynecol Ind. 1990;40:421-4.

7. Vyas PS, Vaidya P. Epidemiology, diagnosis and management of ectopic pregnancy- an analysis of 196 cases. Bombay hospital journal. 2000;42(3):45865.

8. Panti A, Ikechukwu NE, Lukman OO, Yakubu A, Egondu SC, Tanko BA. Ectopic pregnancy at Usmanu Danfodiyo University teaching hospital Sokoto: a ten year review. Annals of Nigerian Medicine. 2012;6(2):87-91.

9. Rakhi, Mital PL, Hooja N, Agarwal A, Makkar P, Andleeb F. Ectopic pregnancy: a devastating catastrophe. Scholars Journal of Applied Medical Sciences (SJAMS) Sch J App Med Sci. 2014;2(3A):903-7.

10. Pendse V. Ectopic pregnancy-a review of 110 cases. J Obstet Gynecol Ind. 1981;31:100-5.

11. Jophy R, Thomas A, Mhaskar A. Ectopic pregnancy - 5 year experience. J Obstet Gynecol Ind. 2002;52:55-8.

12. Majhi AK, Roy N, Karmakar KS, Banerjee PK. Ectopic pregnancy- an analysis of 180 cases. J Indian Med Assoc. 2007;105(6):308-12.

13. Gupta U, Sharma P. Ectopic pregnancy-a prospective analysis of 100 cases. J Obstet Gynecol Ind. 1992;42:597-600.

14. Igwegbe AO, Eleje GU, Okpala BC. An appraisal of the management of ectopic pregnancy in a Nigerian tertiary hospital. Ann Med Health Sci Res. 2013;3(2):166-70

15. Choudhary NN, ROY. A study of 158 cases of Ectopic pregnancy. J Obst Gynecol Ind. 1968;18:364-9.

Cite this article as: Yadav DP, Bhati I, Bhati BS. Ectopic pregnancy: a comprehensive analysis of risk factors and management. Int J Reprod Contracept Obstet Gynecol 2016;5:2723-7. 